\title{
LXIV. On capillary attraction
}

\section{Rev. J.B. Emmett}

To cite this article: Rev. J.B. Emmett (1827) LXIV. On capillary attraction , Philosophical Magazine Series 2, 1:5, 332-336, DOI: 10.1080/14786442708674322

To link to this article: http://dx.doi.org/10.1080/14786442708674322

曲 Published online: 10 Jul 2009.

Submit your article to this journal 준

LII Article views: 2

Q View related articles $₫$ 
LXIV. On Capillary Attraction. By the Rev. J. B. Emvetr.**

[Continued from p. 118.]

$7 \mathrm{HE}$ force which elevates a column of liquid in a fine tube, between two plain surfaces, or around solid matter generally, is corpuscular: the effect is produced by either the surface only of the solid, or a stratum of immeasurably small depth. The liquid is elevated by the attraction of the solid to its upper strata: for, if the upper strata alone of the suspended column be heated, as great an effect is produced as by heating the whole column to the same temperature, which is apparent when the mechanical principles upon which the phænomenon depends are considered.

This fact I did not ascertain until very recently: I had gone through a long series of experiments, using a test tube which contains the liquid, into which is inserted the capillary tube, along which an index moveable by a fine screw, having a divided head, slides : the liquid having arrived at its proper altitude, the whole was plunged into water or other liquid heated to a given temperature, the index being a little above the surface. After having repeated a great number of experiments, many of which were anomalous, I found those which had occupied several weeks wholly useless. The whole series must be repeated by help of an apparatus, which will allow the summit of the column to be seen, and by which any required temperature may be applied to the npper part only. These experiments being useless, I was not able to communicate a paper for the last Number.

In the former paper, I showed that if the density of a liquid be changed by expansion or contraction, the altitude of the column is not affected. This may be proved experimentally:Heat as much as possible of the capillary column, except the upper strata, and no sensible effect is produced: apply the same temperature to the upper part, and a notable depression takes place, such as 3 or 4 parts in 20; even the heat of the hand causes a depression of about $\frac{1}{50}$ th of an inch in a column of $2 \frac{2}{10}$ inches.

I now proceed to investigate the phænomena of such compounds as saline solutions, dilute acids, \&c. Let there be two substances, $A$ and $B$; let the compound be $\mathrm{C}$.

$$
\text { Let } \begin{aligned}
a & =\text { sp.gr. A } b=\text { sp.gr. B } \quad c=\text { sp.gr. C } \\
d & =\text { weight of } \mathrm{A} e=\text { weight } \mathrm{B} f=\text { weight } \mathrm{C}=d+e \\
\mathrm{H} & =\text { altitude to which A is elevated; } h=\text { altitude B; } \\
h^{\prime} & =\text { altitude of } \mathbf{C} .
\end{aligned}
$$$$
\text { * Communicated hy the Author. }
$$ 
The volume of $\mathrm{A}=\frac{d}{a}$; volume of $\mathrm{B}=\frac{e}{b}$; volume of $\mathrm{C}$ $=\frac{d+e}{c}$.

But since each substance $A, B$, is diffused throughout the whole volume,

$$
\frac{d+e}{c}: \frac{d}{a}:: a: \text { density of } \mathrm{A} \text { in its diffused state }=\frac{d c}{d+e} ;
$$

also $\frac{d+e}{c}: \frac{e}{b}:: b:$ density of $\mathrm{B}$ in its diffused state $=\frac{e c}{d+e}$. Hence, (Note $f$, p. 118, No. for February)

Force of $\mathrm{A}=\mathrm{H} \cdot \frac{d c}{d+e}$; force of $\mathrm{B}=h \cdot \frac{e c}{d+e}$; and the sum of these forces is equal to the force of the compound $h^{\prime} c$; i. e.

and

$$
\begin{aligned}
& \frac{\mathrm{H} d+h e}{d+e}=h^{\prime} \ldots \ldots \ldots \ldots \\
& \frac{h^{\prime}\{d+e\}-\mathbf{H} d}{e}=h \ldots \ldots \ldots
\end{aligned}
$$

But if, as generally happens, three tubes of different diameters $\Delta, \delta, \&$, are used respectively for the liquids $A, B, C$; then

$$
h^{\prime}=\frac{\Delta \mathrm{H} a+\delta h e}{\delta^{\prime}\{a+e\}} \ldots \ldots \ldots \ldots
$$

Again: since the force of attraction is proportional to the altitude of the column, multiplied into the density of the liquid, in the same tube;

$$
\text { Force of } \mathrm{C}=h^{\prime} c=\frac{\{\mathrm{H} d+h e\} . c}{d+e} \ldots \ldots
$$

By transposing the equations $c$ and $d$, the forces of attraction may be found under all circumstances.

The primary formula (a) may be derived more simply, but not so satisfactorily, thus :

Force of $\mathrm{A}=\mathrm{H} d$; force of $\mathrm{B}=h e$; force of $\mathrm{C}=h^{t}$ $\{d+e\}$; the same tube being used.

But $\mathrm{H} d+h e=h^{\prime}\{d+e\}$; therefore $h^{\prime}=\frac{\mathbf{H} d+h e}{d+e}$, as before.

In any solution or compound $d$ and $e$ being known; and $\mathrm{H}$ and $h^{2}$, or $\mathrm{H}$ and $h^{\prime}$, or $h$ and $h^{\prime}$ being found by experiment, the force may be found, when the tubes are equal, by formula $(a)$ or $(b)$; or in unequal tubes by $(c)$, or $(c)$ transposed, if $\mathrm{H}$ or $h$ be required: and the force of attraction between the solid and the compound, or the solid and one of the component parts of the liquid at any temperature is found by $(d)$.

The following table exhibits a few results, the data of the annexed 
annexed calculations: I take the altitude of water as the standard :
Name of the Liquid.
Altitude.
1. Water ............. 100
2. Sat. sol. muriate of ammonia .... $102 \cdot 7$
3. - sulphate of potash ..... 95.7
4. - sulphuret of potash .... 95.2
6. — muriate of soda ..... 88.2
7. - sulphate of copper . . ... 84.0
8. Nitric acid .......... $75^{\circ} 0$
9. Muriatic acid .......... $70 \cdot 1$
5. Oil of tartar per deliq. ....... $88 \cdot 4$
10. Essential oil of lemon . . . . . . . 4 $42 \cdot 8$
11. Alcohol ............. 40.8
12. Refined whale oil ......... $37 \cdot 5$
13. Oil of lavender .......... . $37 \cdot 5$

Oil of turpentine, Oil of olives, and Sulphuric æther, nearly the same with $11,12,13$.

This table exhibits the relative altitudes to which the liquids are elevated; and since it was shown in the former paper, that a change in the density produced by variation of temperature, does not affect the height of the column, these numbers represent the ratios of the forces of attraction between the glass and one particle of the liquid, at the distance to which they are kept asunder by the repulsive force of caloric: and if the force of attraction of the liquid to the solid be required at any temperature, multiply the altitude by the density of the liquid. at that temperature.

The following are some effects of combination:

Exp. 1. Saturated solution of subcarbonate of potash, was elevated 23 tenths of an inch . . . . = h

Water in the same tube 26.25 tenths . . . . . = H

Mixture of one volume water, and one volume soIution $24 \cdot 25$ or $24 \cdot 5$ tenths . . . . . . . . = $=h^{\prime}$

$d=1 ; e=1 \cdot 5$.

By formula $(a), h^{\prime}=24.3$; which is between the two values of $h^{\prime}$, found by experiment.

Exp. 2. Solution of sulphate of potash (sp. gr. 1.0328) was elevated 89 divisions of the scale.

Altitude of water $=\mathrm{H}=93 \quad d=54.8$

By formula $(a) \quad h^{\prime}=90 \cdot 9$.

$$
h=89 \quad e=56.6
$$

Exp. 3. Solution of muriate of soda $\ldots h=22.5$

Water .............. H $=25.5$

Mixture of equal volumes $\ldots \ldots \ldots h^{\prime}=23 \cdot 5$.

The formula accords closely with the experiment. 
Exp.4. Solution of sulphate of copper $h=95 \quad d=54$

$$
\text { water } H=113 \quad e=58
$$

1 vol. of solution +1 vol. water $h^{\prime}=108$

By the formula, $h^{\prime}=103 \cdot 6$.

$$
\begin{array}{rlr}
\text { Exp. 5. Alcohol } \ldots \ldots & h=7 . & d=100 \\
\text { Water } \ldots \ldots & \mathrm{H}=22^{\circ} & e=83 \\
1 \text { vol. alcohol }+1 \text { water } h l^{\prime}=7 \cdot 8 . &
\end{array}
$$

By formula $(b), h=-9 \cdot 3$; but by experiment $h=7$.

By formula $(a), h^{\prime}=15 \cdot 2$; by experiment $h^{\prime}=7 \cdot 8$.

Hence the altitude to which any liquid, mixture or combination of liquids is raised, does not depend solely upon the density or densities of the substances concerned: this is evident from Exp. 5; in which, 100 by weight of water, added to 83 of alcohol, causes an addition of $\frac{8}{7}$ th only to the column of pure alcohol; although the height of the column of water : that of alcohol : : $100: 40 \cdot 8$. So extraordinary a phænomenon cannot result from any mechanical law depending upon the relative weight or specific gravity of the component parts; it is more analogous to chemical attraction, and capillary phænomena will afford a measure of corpuscular forces, as well as of their increase and decrease, so far as depends upon distance.

The phænomena of alcohol present apparent anomalies; but they are so constant, that a thorough investigation will develop some of the primary laws of corpuscular forces: the appearances may be partially accounted for by considering that alcohol consists of the elements of $51 \cdot 15$ olefiant (bicarburetted hydrogen) gas, and 31.85 water ; the former of which must be repulsive to glass, since a small quantity of alcohol greatly depresses a column of water: thus, 100 water +83 alcohol rose to $6.66 \mathrm{elev}$; 1 vol. of this mixture +3 water rose to $10.5 ; 1$ vol. mixture +7 water was elevated 13; water alone 16: in this experiment (since 100 alcohol consists of 61.63 olefiant gas +38.37 water), 100 of the mixture, proof strength, contains 27.95 olefiant gas +72.05 water; its altitude was 6.66 ; pure water $16 ; 27.95$ olefiant gas +372.05 water rose to $10.5 ; 27.95$ olefiant gas +772.05 water rose but to $13 ; i . e$. if to 100 parts by weight of water, 3.62 of liquid bicarburetted bydrogen gas, as it exists in alcohol, be added, the column is less by $\frac{3}{16}$ th than that of pure water.

If the altitude $h$, to which the liquid olefiant gas alone will rise, be calculated, we find by the experiment on alcohol, that it is -2.2 ; whilst, by that on the mixture of equal volumes of alcohol and water, it is about -29 .

Whether these curious results arise from an actual force of repulsion between the glass and the olefiant gas, or whether it arises simply from the cohesive force of the upper strata of 
the water (on which the effect depends) being diminished by the mixture of the alcohol, is not apparent.

Another singular example of the agency of heat in effecting a diminution of corpuscular attraction presents itself in the following experiment:-Cut two pieces of soft lead, so that each may have a plain and bright surface; by pressure these surfaces may be made to cohere with considerable force. Suspend the pieces one perpendicularly over the other, and to the lower piece hang weights, nearly as heavy as the cohesive force may be supposed capable of supporting. 'The application of a degree of heat, not superior to that of boiling water, will cause a separation, provided the weights be sufficiently heavy : whence the corpuscular force of heat produces sensible effects at minute, even sensible distances.

The phænomena of the capillary action of parallel metallic plates are curious. I have made a considerable number of experiments; but until some difficulties shall be surmounted, they cannot be in a state to be submitted to public scrutiny.

An apology is due to you as well as to your readers, for the delay-after I had promised to continue the subject in your last Number: however, I am certain it will not be required, when it is considered that the manufacture of all my own apparatus, which the small resources of a country curacy make requisite, often requires ten times the time which the experimental researches occupy. In addition, the discovery that the column is suspended by the upper stratum only, rendered the experiments of several weeks quite useless, and demands the application of apparatus of a new construction, which is now nearly complete.

[To be continued.]

LXV. On the Velocity of Sound. By W.Galbrayrrh, Esq.M.A.

\section{To Richard Taylor, Esq.}

Sir,

N the 68th volume of the Philosophical Magazine, page 214, I gave a short paper On the velocity of sound transmitted through the atmosphere. In it I endeavoured to investigate an accurate and commodious formula for determining the velocity of sound under given circumstances, embracing all those minutix affecting it, so far as I was acquainted with them. In a note, (pages 215 and 216,) I mentioned the values of the constant generally introduced in the late investigations of this question, and hinted that a mean of the whole of these, namely 1.4112, was more conformable to the velocity of sound by ex- 